\title{
Perceived Obstacles Faced by Diabetes Patients Attending University of Gondar Hospital, Northwest Ethiopia
}

\author{
Akshaya Srikanth Bhagavathula ${ }^{1 *}$, Eyob Alemayehu Gebreyohannes', \\ Tadesse Melaku Abegaz ${ }^{1}$ and Tamrat Befekadu Abebe ${ }^{1,2}$
}

'Department of Clinical Pharmacy, School of Pharmacy, University of Gondar-College of Medicine and Health Sciences, Gondar, Ethiopia, ${ }^{2}$ Department of Learning, Informatics, Management and Ethics (LIME), Karolinska Institutet, Solna, Sweden

OPEN ACCESS

Edited by:

Tahir Mehmood Khan, Monash University Malaysia,

Malaysia

Reviewed by:

Akinobu Nakamura,

Hokkaido University, Japan

Amer Hayat Khan,

University of Science, Malaysia,

Malaysia

*Correspondence:

Akshaya Srikanth Bhagavathula akshaypharmd@gmail.com

Specialty section:

This article was submitted

to Diabetes,

a section of the journal

Frontiers in Public Health

Received: 23 January 2018 Accepted: 05 March 2018

Published: 27 March 2018

Citation:

Bhagavathula AS,

Gebreyohannes EA, Abegaz TM and Abebe TB (2018) Perceived

Obstacles Faced by Diabetes

Patients Attending University of Gondar Hospital, Northwest Ethiopia.

Front. Public Health 6:81.

doi: 10.3389/fpubh.2018.00081
Background: Diabetes mellitus (DM) is a non-communicable, chronic, and progressive disease that can lead to serious complications and even to premature death. A closer understanding of the DM patients' specific obstacles will provide a greater clarity of the factors influencing their disease-related quality of life and coping with daily life. The study aimed to evaluate the obstacles of DM patients attending ambulatory clinic of the University of Gondar Hospital (UOGH), Northwest Ethiopia.

Methods: A cross-sectional study was conducted from February to April 2017 at ambulatory clinic of the UOGH. A validated short version of the diabetic obstacle questionnaire was used. The internal reliability of the questionnaire was checked using Cronbach's alpha and was found to be $92.5 \%$. To determine any association between each of the nine sections of the questionnaire and age, sex, residence, educational status, and DM type, a binary logistic regression was performed.

Results: The mean age of respondents was $38.69 \pm 15.39$ years. Compared with patients with type $1 \mathrm{DM}$, patients with type $2 \mathrm{DM}$ reported poorer relationships with medical professionals (adjusted odds ratio $(A O R)$ : 2.191, $p$-value $=0.027$ ) and less support from families and friends (AOR: 1.913, $p$-value $=0.049$ ). Patients coming from rural areas (AOR: 2.947, $p=0.002$ ) and having no formal education (AOR: 2.078, $p=0.029$ ) also received less support from families and friends.

Conclusion: DM patients in UOGH reported several obstacles related to patients' relationship with health professionals, lack of support from their friends, lack of knowledge about DM, and lack of motivation to exercise. Effective efforts should be initiated to improve healthier environment to educate, care and preventive services for people with DM.

Keywords: diabetes mellitus, self-care, diabetes obstacles, Gondar, Ethiopia

\section{INTRODUCTION}

Diabetes mellitus (DM) is a non-communicable, chronic, and progressive disease that can lead to serious complications and even to premature death. The 2014 global estimates showed that 422 million adults were living with DM. It is no longer a disease of only developed nations and has been increasingly affecting developing countries as well (1). In sub-Saharan Africa (SSA), an estimated 
14.2 (9.5-29.4) million people aged 20-79 have diabetes, a figure that is expected to increase to 34.2 million by 2040 (2).

Diabetes mellitus is known to influence the patients' physical, social, and psychological well-being (3). Poor diet, lack of physical activities, and poor self-monitoring of glucose levels are some of the most common obstacles faced by DM patients (3-6). Better glycemic control can progressively prevent or delay complications and improve quality of life (QOL). On the other hand, lack of attention, insufficient time to provide patientspecific education, and overcrowding of health institutions by DM patients are some of the perceived translational obstacles faced by the healthcare providers (7). A closer understanding of the DM patients' specific obstacles will provide a greater clarity of the factors influencing their disease-related QOL and coping with daily life.

Several studies were conducted using different diabetesspecific QOL instruments conducted on target population (type 1 or type 2 or both) among different ethnic communities and countries (8). However, popular scales such diabetesrelated QOL, the Audit of Diabetes-Dependent Quality of Life (ADDQOL), and Problem Areas in Diabetes (PAID) have been widely used across different populations. In contrast, the Diabetes Health Profile (DHP), Questionnaire on Stress in Diabetes Patients-Revised (QSD-R), and Diabetes Quality of Life Clinical Trials Questionnaire (DQLCT-R) have not been used in any studies (8). All these scales frequently measured health-related QOL (HRQOL) and little attention was given to understand the patient-specific obstacles. Furthermore, considering selection of Africans, only few studies assessed adherence (9), mental health outcomes (10), and two randomized controlled trials $(11,12)$ conducted on African-American communities with DM. In the context of DM patients in SSA, no studies were identified investigating DM patients-specific obstacles in Ethiopia. Therefore, the study aimed to evaluate the obstacles of DM patients attending ambulatory clinic of the University of Gondar Hospital (UOGH), Northwest Ethiopia.

\section{MATERIALS AND METHODS}

\section{Study Design and Setting (Area and Period)}

A cross-sectional study was conducted from February to April 2017 at the ambulatory clinic of the UOGH. UOGH is located in the north-west part of Ethiopia $727 \mathrm{~km}$ from the capital city Addis Ababa.

\section{Operational Definition}

- Type 1 DM: also known as insulin-dependent diabetes mellitus (IDDM) caused by $\beta$-cell failure and severe or absolute insulin deficiency (13).

- Type 2 DM: also known as non-insulin dependent diabetes mellitus (NIDDM) is a complex multisystem disease with carbohydrate and lipid metabolic derangements, characterized by vascular inflammation. All characterized by elevated glycemic markers caused by a secretory defect of insulin on the background of insulin resistance (13)
- Formal education: having at least primary-school education

- Rural areas: a residential area located outside the towns and cities

\section{Sample Size}

An online sample size calculator "Creative research systems" (14) was used to determine the number of DM participants for the study, by considering $95 \%$ confidential level, with an accuracy of $50 \%$ for the population of 2,125 registered DM patients at the outpatient department of the UOGH (15) has given a confidential level of 6.42, recommended a sample size of 210 .

\section{Study Population}

Type 1 and type 2 diabetic patients attending ambulatory clinic during the study period were recruited and included in the study. However, patients with cognitive impairment, severely sick, and who did not consent to participate in the study were excluded.

\section{Study Instrument}

The validated short version of the diabetic obstacle questionnaire (DOQ-30) was developed by researchers and was validated in six European countries (6). Permission was obtained to reuse from the corresponding author. The questionnaire consisted of a total of 30 questions that were divided in to nine sections addressing different issues: relationships with medical professionals (four items), support from friends and families (four items), knowledge of the disease (four items), lifestyle changes (four items), self-monitoring (four items), uncertainty about a consultation (two items), medication (two items), and insulin use (two items). A 4-point Likert scale ( $1=$ Strongly disagree, $2=$ Disagree, $3=$ Agree, and $4=$ Strongly agree) was used to obtain their responses. Before the questionnaire was administered to patients, it was first translated into Amharic by two of the investigators (EAG and TMA) and then back-translated to English by another investigator (TBA) to verify for accuracy. The translated questionnaire was pretested among 20 randomly selected DM patients for reliability and validity. No language problems and corrections were requested. The questionnaire was basically self-administered; however, in cases where the patients were not able to read and write interview method was employed. Sufficient time was given for the patients to fill the questionnaire during their waiting time. Any discrepancies were dealt with discussion. The internal reliability of the questionnaire was checked using Cronbach's alpha and was found to be $92.5 \%$.

\section{Ethical Consideration}

Ethical clearance was obtained from the ethical clearance committee of the school of pharmacy. Before the questionnaire was administered to patients, the aim of the study was explained to patients, and written and verbal informed consent was obtained from each patient prior to their participation. The information obtained from patients was kept confidential and was used for the study purpose only. All the patients in the study were voluntary and no compensation was provided. Furthermore, confidentiality was maintained by not disclosing any personal information of the study participants and their responses were randomized. 


\section{Statistical Analysis}

Descriptive statistics were used to summarize sociodemographic characteristics and ratings of the different components of the questionnaire by the study participants. To determine any association between each of the nine sections of the DOQ-30 and age, sex, residence, educational status, and DM type a binary logistic regression was performed. To do so, an average score of the items ( 1 to 4 in the Likert scale) in each of the eight sections was made. Then the nine sections were dichotomized into two: Strongly disagree/Disagree if the average score was $\leq 2$ and Agree/Strongly Agree if the average score was $>2$.

\section{RESULTS}

\section{Baseline Characteristics of Respondents}

Of 210 patient approached, 202 subjects responded to the questionnaire, giving a $96.2 \%$ response rate. The mean \pm SD age of respondents was $38.69 \pm 15.39$. Majority of the study participants were male (61.9\%) and came from urban areas $117(57.9 \%)$ (Table 1).

Majority of the patients (57.4\%) were having type 1 DM. Nearly two-third of patients $(67.3 \%)$ were taking a single anti-diabetic agent of which insulin was the most commonly used one (57.9\%). The remaining patients were using a combination of antidiabetic medications (Table 2).

\section{Relationship With Health Professionals and Support From Friends and Family}

With the exception of the "I am not assisted in setting realistic targets for changing my lifestyle." item, nearly two-third of the respondents reported that they have a poor relationship with health professionals. Majority of the participants reported getting poor social support from their friends (53.5\%) and feeling lonely with their disease $(51.5 \%)$, but received but good social support from their family (53.3\%) and showed good attitude to manage DM had they had support from others $(54.5 \%)$ (Table 3).

\section{Knowledge About Diabetes, Lifestyle Changes, and Exercise}

The greater number of DM patients reported having poor knowledge about the disease in terms of understanding information from literature (56.4\%), managing their diabetes $(53.5 \%)$, consequences of diabetes (59.4\%), and treatment for diabetes (57.9\%). On the other hand, less than half of the respondents reported having difficulty with lifestyle changes while most of the respondents reported that they faced different challenges to do regular physical exercise (Table 3).

\section{Medication Appropriateness and Insulin Use}

More than half of respondents (56.4\%) agreed that they received the right dose while two-thirds of them (66.3\%) stated that the type of antidiabetic agent was appropriate for their disease. In addition, most of the patients reported that insulin use neither complicates their life (56.9\%) nor is a sign of worsening of their diabetes (53.0\%) (Table 3).
TABLE 1 | Demographic characteristics of diabetic patients in University of Gondar Hospital ( $N=202)$.

\begin{tabular}{|c|c|}
\hline Characteristics & Frequency (\%) \\
\hline Mean age $\pm S D$ & $38.69 \pm 15.393$ \\
\hline \multicolumn{2}{|l|}{ Sex } \\
\hline Male & 125 (61.9\%) \\
\hline Female & $77(38.1)$ \\
\hline \multicolumn{2}{|l|}{ Residence } \\
\hline Urban & $117(57.9)$ \\
\hline Rural & $85(42.1)$ \\
\hline \multicolumn{2}{|l|}{ Marital status } \\
\hline Single & $63(31.2)$ \\
\hline Married & $113(55.9)$ \\
\hline Divorced & $21(10.4)$ \\
\hline Widowed & $5(2.5)$ \\
\hline \multicolumn{2}{|l|}{ Education level } \\
\hline No formal education & $85(42.1)$ \\
\hline Primary & 47 (23.3) \\
\hline Secondary & 33 (16.3) \\
\hline College and above & 37 (18.3) \\
\hline \multicolumn{2}{|l|}{ Occupation } \\
\hline None & $3(1.5)$ \\
\hline Student & 39 (19.3) \\
\hline Merchant & $30(14.9)$ \\
\hline Government employee & 39 (19.3) \\
\hline Farmer & $84(41.6)$ \\
\hline Daily laborer & 7 (3.5) \\
\hline \multicolumn{2}{|c|}{ Monthly income (Ethiopian Birr) } \\
\hline Less than 500 & $115(56.9)$ \\
\hline 500-999 & $11(5.4)$ \\
\hline $1,000-1,999$ & $35(17.3)$ \\
\hline 2,000-3,000 & $41(20.3)$ \\
\hline
\end{tabular}

TABLE 2 | Disease and treatment characteristics of diabetic patients in University of Gondar Hospital $(N=202)$.

\begin{tabular}{lc}
\hline Characteristics & Frequency (\%) \\
\hline Type of diabetes & $116(57.4)$ \\
Type 1 & $86(42.6)$ \\
Type 2 & \\
Number of antidiabetic medications used & $136(67.3)$ \\
1 medication & $66(32.7)$ \\
2 medications & \\
Current antidiabetic regimen & $117(57.9)$ \\
Insulin & $17(8.4)$ \\
Metformin & $12(5.9)$ \\
Insulin plus metformin & $17(8.4)$ \\
Insulin plus glibenclamide & $38(18.8)$ \\
Outformin plus glibenclamide & \\
Improved & $155(76.8)$ \\
Not improved & $47(23.2)$ \\
\hline
\end{tabular}

\section{Self-Monitoring}

Self-monitoring was not considered a challenge by most of the patients. Less than half of the respondents reported that selfmonitoring made them frustrated (44.6\%) and fearful of a high 
TABLE 3 | Rating of patients for individual components of diabetes obstacles.

\begin{tabular}{|c|c|c|c|}
\hline Obstacles & Mean \pm SD & $\begin{array}{l}\text { Agree/totally } \\
\text { agree } n(\%)\end{array}$ & $\begin{array}{c}\text { Disagree/totally } \\
\text { disagree } n(\%)\end{array}$ \\
\hline \multicolumn{4}{|l|}{ Relationships with medical professionals } \\
\hline 1. I am not assisted in setting realistic targets for changing my lifestyle & $2.94(1.526)$ & $84(41.6)$ & $118(58.4)$ \\
\hline 2. Treatment alternatives are not explained to me & $3.63(1.481)$ & $128(63.4)$ & $74(36.6)$ \\
\hline 3. I have not been told what to expect from my treatment & $3.7(1.443)$ & $131(64.9)$ & $71(35.1)$ \\
\hline 4. The good and bad aspects of each choice have not been discussed with me & $3.82(1.463)$ & $136(67.3)$ & $66(32.7)$ \\
\hline \multicolumn{4}{|l|}{ Support from friends and family } \\
\hline 5. I feel I get little support from my family & $3(1.71)$ & $94(46.5)$ & $108(53.5)$ \\
\hline 6. I feel I get little support from my friends & $3.24(1.598)$ & $108(53.5)$ & $94(46.5)$ \\
\hline 7. I feel very alone with my diabetes & $3.15(1.509)$ & $104(51.5)$ & $98(48.5)$ \\
\hline 8. I would manage my diabetes much better if I had encouragement socially & $3.24(1.494)$ & $110(54.5)$ & $92(45.5)$ \\
\hline \multicolumn{4}{|l|}{ Knowledge of the disease } \\
\hline 9. I have difficulty understanding the information from literature & $3.39(1.532)$ & $114(56.4)$ & $88(43.6)$ \\
\hline 10. I do not know as much as I need to know to manage my diabetes & $3.35(1.51)$ & $108(53.5)$ & $94(46.5)$ \\
\hline 11. I do not know as much as I need to know about the consequences of having diabetes & $3.58(1.441)$ & $120(59.4)$ & $82(40.6)$ \\
\hline 12. I do not know enough about the treatment for diabetes & $3.41(1.501)$ & $117(57.9)$ & $85(42.1)$ \\
\hline \multicolumn{4}{|l|}{ Lifestyle changes } \\
\hline 13. My diabetes has placed a strain on my personal relationships & $3.18(1.441)$ & $99(49.09)$ & $103(51.0)$ \\
\hline 14. Changes in my diet have put a strain on my family & $3(1.454)$ & $91(45.0)$ & $111(55.0)$ \\
\hline 15. I feel resentful that I am obliged to change my eating habits & $3.1(1.373)$ & $94(46.5)$ & $108(53.5)$ \\
\hline 16. My diabetic diet spoils my social life & $3.19(1.465)$ & $100(49.5)$ & $102(50.5)$ \\
\hline \multicolumn{4}{|l|}{ Exercising } \\
\hline 17. I have not found an exercise I enjoy & $3.25(1.289)$ & $102(50.5)$ & $100(49.5)$ \\
\hline 18. I lack the motivation to exercise & $3.47(1.294)$ & $117(57.9)$ & $85(42.1)$ \\
\hline 19. I am unable to fit exercise into my lifestyle & $3.47(1.309)$ & $116(57.4)$ & $86(42.6)$ \\
\hline 20. I am unable to afford the cost of exercising on a regular basis & $3.21(1.378)$ & $103(51)$ & $99(49)$ \\
\hline \multicolumn{4}{|l|}{ Self-monitoring } \\
\hline 21. Self-monitoring makes me feel frustrated & $3.05(1.445)$ & $90(44.6)$ & $112(55.4)$ \\
\hline 22. I find it too uncomfortable to self-monitor & $2.92(1.417)$ & $81(40.1)$ & $121(59.9)$ \\
\hline 23. I find it especially hard to test when I am busy & $2.92(1.401)$ & $85(42.1)$ & $117(57.9)$ \\
\hline 24. Self-monitoring makes me fearful of a high reading & $2.95(1.422)$ & $82(40.6)$ & $120(59.4)$ \\
\hline \multicolumn{4}{|l|}{ Uncertainty about a consultation } \\
\hline 25. I feel a sense of helpless when consulting with nurses & $2.95(1.411)$ & $79(39.1)$ & $123(60.9)$ \\
\hline 26. The way that I was told that I had diabetes made feel afraid & $2.93(1.475)$ & $82(40.6)$ & $120(59.4)$ \\
\hline \multicolumn{4}{|l|}{ Medication } \\
\hline 27. I do not feel I am being prescribed a medication dose that is right for me & $3.01(1.461)$ & $88(43.6)$ & $114(56.4)$ \\
\hline 28. I do not feel I am being prescribed medication that is right for me & $2.72(1.457)$ & $68(33.7)$ & $134(66.3)$ \\
\hline \multicolumn{4}{|l|}{ Insulin use } \\
\hline 29. Using insulin makes life too complicated & $2.92(1.465)$ & $87(43.1)$ & $115(56.9)$ \\
\hline 30. Using insulin means my diabetes is getting worse & $3.06(1.503)$ & $95(47.0)$ & $107(53.0)$ \\
\hline
\end{tabular}

reading (40.6\%), became uncomfortable to self-monitor $(40.1 \%)$, and found it hard to test when busy (42.1\%) (Table 3).

Binary logistic regression identified few variables as independent predictors of higher frequency of obstacles among diabetic patients. Compared with patients with type $1 \mathrm{DM}$, patients with type $2 \mathrm{DM}$ reported poorer relationships with medical professionals [AOR (95\% CI): $2.191(1.092-4.399), p$-value $=0.027$ ] and less support from families and friends [AOR $(95 \% \mathrm{CI})=1.913$ (1.002-3.653), $p$-value $=0.049]$. Patients coming from rural areas [AOR (95\% CI): $2.947(1.485-5.848), p=0,002]$ and having no formal education [AOR (95\% CI): 2.078 (1.08-3.998), $p=0.029$ ] also received less support from families and friends. Coming from rural areas was associated with having poorer knowledge [AOR (95\% CI): 10.132 (4.492-22.851), $p=0.000$ ] and facing difficulties with lifestyle changes [AOR (95\% CI): 3.45 (1.792-6.64), $p=0.000$ ], exercising [AOR (95\% CI): 4.859 (2.279-10.359), $p=0.000$ ], self-monitoring [AOR (95\% CI): 4.817 (2.551-9.097), $p=0.000$ ], and insulin use [AOR (95\% CI): 2.082 (1.179-3.675), $p=0.011]$. Similar obstacles were also reported by patients having no formal education (Table 4). 
TABLE 4 | Diabetes obstacles and associated factors.

\begin{tabular}{|c|c|c|c|c|c|c|c|c|c|}
\hline \multirow[t]{2}{*}{ Characteristics } & \multirow[t]{2}{*}{ Age } & \multicolumn{2}{|r|}{ Sex } & \multicolumn{2}{|r|}{ Residence } & \multicolumn{2}{|r|}{ Education } & \multicolumn{2}{|r|}{ DM type } \\
\hline & & Male & Female & Urban & Rural & $\begin{array}{c}\text { Formal } \\
\text { education }\end{array}$ & $\begin{array}{l}\text { No formal } \\
\text { education }\end{array}$ & Type 1 & Type 2 \\
\hline \multicolumn{10}{|c|}{ Relationships with medical professionals } \\
\hline $\operatorname{AOR}(95 \% \mathrm{Cl})$ & $1.016(0.994-1.039)$ & 1 & $1.093(0.561-2.127)$ & 1 & $1.358(0.699-2.635)$ & 1 & $1.484(0.759-2.899)$ & 1 & $2.191(1.092-4.399)$ \\
\hline$p$-Value & 0.154 & & 0.794 & & 0.366 & & 0.248 & & 0.027 \\
\hline \multicolumn{10}{|c|}{ Support from friends and family } \\
\hline $\operatorname{AOR}(95 \% \mathrm{Cl})$ & $1.019(0.998-1.041)$ & 1 & $1.198(0.633-2.268)$ & 1 & $2.947(1.485-5.848)$ & 1 & $2.078(1.08-3.998)$ & 1 & $1.913(1.002-3.653)$ \\
\hline$p$-Value & 0.074 & & 0.578 & & 0.002 & & 0.029 & & 0.049 \\
\hline \multicolumn{10}{|c|}{ Knowledge of the disease } \\
\hline $\operatorname{AOR}(95 \% \mathrm{Cl})$ & $1.035(1.013-1.057)$ & 1 & $1.091(0.597-1.994)$ & 1 & $10.132(4.492-22.851)$ & 1 & 4.347 (2.205-8.569) & 1 & $1.736(0.947-3.183)$ \\
\hline$p$-Value & 0.002 & & 0.778 & & 0.000 & & 0.000 & & 0.074 \\
\hline \multicolumn{10}{|c|}{ Lifestyle changes } \\
\hline $\operatorname{AOR}(95 \% \mathrm{Cl})$ & $1.001(0.982-1.021)$ & 1 & $1.2(0.654-2.199)$ & 1 & $3.45(1.792-6.64)$ & 1 & $2.046(1.105-3.789)$ & 1 & $0.831(0.461-1.497)$ \\
\hline$p$-Value & 0.885 & & 0.556 & & 0.000 & & 0.023 & & 0.831 \\
\hline \multicolumn{10}{|l|}{ Exercising } \\
\hline $\operatorname{AOR}(95 \% \mathrm{Cl})$ & $1.015(0.994-1.036)$ & 1 & $1.432(0.747-2.745)$ & 1 & $4.859(2.279-10.359)$ & 1 & $2.24(1.153-4.354)$ & 1 & $0.805(0.433-1.497)$ \\
\hline$p$-Value & 0.177 & & 0.28 & & 0.000 & & 0.017 & & 0.493 \\
\hline \multicolumn{10}{|l|}{ Self-monitoring } \\
\hline $\operatorname{AOR}(95 \% \mathrm{Cl})$ & $1.003(0.985-1.022)$ & 1 & $1.42(0.793-2.544)$ & 1 & $4.817(2.551-9.097)$ & 1 & $2.675(1.475-4.852)$ & 1 & $0.703(0.399-1.238)$ \\
\hline$p$-Value & 0.738 & & 0.238 & & 0.000 & & 0.001 & & 0.222 \\
\hline \multicolumn{10}{|c|}{ Uncertainty about a consultation } \\
\hline $\operatorname{AOR}(95 \% \mathrm{Cl})$ & $1.002(0.984-1.02)$ & 1 & $1.064(0.603-1.878)$ & 1 & $1.588(0.904-2.789)$ & 1 & $1.875(1.064-3.305)$ & 1 & $0.674(0.385-1.181)$ \\
\hline$p$-Value & 0.811 & & 0.831 & & 0.108 & & 0.03 & & 0.168 \\
\hline \multicolumn{10}{|l|}{ Medications } \\
\hline $\operatorname{AOR}(95 \% \mathrm{Cl})$ & $1.013(0.995-1.032)$ & 1 & $1.002(0.568-1.769)$ & 1 & $2.521(1.421-4.474)$ & 1 & $1.957(1.11-3.447)$ & 1 & $0.976(0.559-1.706)$ \\
\hline$p$-Value & 0.159 & & 0.994 & & 0.002 & & 0.02 & & 0.933 \\
\hline \multicolumn{10}{|l|}{ Insulin use } \\
\hline $\operatorname{AOR}(95 \% \mathrm{Cl})$ & $1.026(1.007-1.045)$ & 1 & $1.643(0.927-2.913)$ & 1 & $2.082(1.179-3.675)$ & 1 & $3.204(1.787-5.745)$ & 1 & $1.688(0.962-2.963)$ \\
\hline$p$-Value & 0.008 & & 0.089 & & 0.011 & & 0.000 & & 0.068 \\
\hline
\end{tabular}

Significant at $P<0.05$ were bolded.

\section{DISCUSSION}

The current research assessed the obstacles faced by both type 1 and type $2 \mathrm{DM}$ patients attending the ambulatory clinic of UOGH. Based on the findings of this study, poor relationship with health professionals, lack of support from their friends, and feeling lonely with their disease were reported as obstacles by more than half of the DM patients. However, poor knowledge about the disease and obstacles to take medications properly were also reported as obstacles by the patients. There were few differences between type 1 and type 2 DM patients in the reported intensity of obstacles. In the present study, type 1 DM patients and type 2 DM patients significantly differed in their relationship with medical professionals, and receiving support from family and friends. Other studies also reported difference in obstacles faced by patients with type 1 and type 2 $\operatorname{DM}(16,17)$.

These data point to three major types of diabetes obstacles: the desire to have a good relationship with the health professionals, and more broadly, willing to take support from their family and friends, and lack of knowledge about DM is making them feel lonely (burden). It is noteworthy that there were relatively few consistent differences in factor scores among patient characteristics (age, sex, and type of DM) pointing to the potential generalizability of the obstacles faced across the DM population.

Lower level of education and living in rural areas were independently associated with poor family and friends support, lack of knowledge about DM, poor lifestyle changes, less-frequent exercising, and poor self-monitoring and medication use process. Furthermore, we note that these factors remained unchanged even after adjusting for their age, sex and type of DM. This suggests that these are main driving obstacles faced by DM patients in our population.

Non-availability of professional care team (specialists, nurses, dietitians, and diabetes educators), poor healthcare infrastructure, a strong culture of hospitality and frequent fasting has nudged the Ethiopian rural societies. Several obstacles were also identified for the poor DM management such as poor self-monitoring of blood glucose, including lower socioeconomic positions, education levels, social class, and living in a high poverty (18). These suggest that patients with DM might be more likely to follow health professionals' recommendations to improve their DM knowledge and QOL. Most of our study participants agreed that their medical professionals did not provide time to explain treatment alternatives, and good and bad about their care. This explains the time spent by the medical professional to patients 
is low. Improving communication amongst doctors, nurses, pharmacists and patients can play a central role in improving peer support, understand patient-specific needs, and facilitate compliance, and self-motivation to control diabetes (19-22). Family members and friends can actively support and care the DM patients. Several studies have highlighted the importance of family, friends, and colleagues in improving well-being and self-management of DM (23-26). Most of our study participants opinioned that they receive little support from friends, feel very lonely because of DM and further, they are confident to manage DM if they receive social support. Family members are often asked to share in the responsibility of disease management. Their support can drive patient to fix their appointments, or helping inject insulin, and social and emotional support in helping patients cope with DM (27-29). Engaging family members or friends in diabetes education program can have a greater improvement in increasing knowledge of DM, glycemic control, and provide instrumental and social support than the patients alone.

DM-related knowledge is essential to cope with emotional aspects, glycemic control, and to prevent DM-related complication. Several studies assessed psychosocial outcomes found some improvement in DM patients' depressive symptoms, DM-related destress, self-efficacy, perceived social support, and DM-related QOL (30-33). But, several studies found no change in their improvement in only some self-care behaviors. Understanding these discrepancies, educating patients along with their family members about diabetes-care needs can help them to understand the importance of lifestyle modifications, exercise routines, and healthy recipes, ultimately alter disease progression.

Most of the DM patients believe that DM should only be treated with oral medications and insulin injections. It is evident from the previous studies that most of the DM patients rarely change their diet or exercise habits after they were diagnosed (34-36). In our study, around $40 \%$ of the participants reported that they were not well informed about their medications and feeling that using insulin may worsen their DM. In order to minimize such misconceptions and beliefs, health professionals especially pharmacists' need to educate patients about their medications to improve their level of medication adherence and consequently therapeutic outcomes.

Our study had few limitations. First, a self-reported method was used to assess DM patients' obstacles. Therefore, respondents

\section{REFERENCES}

1. World Health Organization. Global Status Report on Diabetes. Geneva: World Health Organization (2016).

2. International Diabetes Federation. IDF Diabetes Atlas. 7th ed. Brussels, Belgium: International Diabetes Federation (2015).

3. Hall FR, Joseph DH, Schwartz-Barcott D. Overcoming obstacles to behavior changes in diabetes self-management. Diabetes Educ (2003) 29(2):303-11. doi:10.1177/014572170302900221

4. Gandhi GY, Murad MH, Fujiyoshi A, Mullan RJ, Flynn DN, Elamin MB, et al. Patient-important outcomes in registered diabetes trials. JAMA (2008) 299(21):2543-9. doi:10.1001/jama.299.21.2543

5. Pilv L, Rätsep A, Oona M, Kalda R. Prevalent obstacles and predictors for people living with type 2 diabetes. Int J Family Med (2012) 2012:842912. doi:10.1155/2012/842912

6. Pilv L, Vermeire E, Ratsep A, Moreau A, Nikolic D, Petek D, et al. Development and validation of short version of the diabetes obstacles questionnaire may underestimate or overestimate their DM-related obstacles. More precise estimates of real-life obstacles of patients can be obtained through qualitative methods. However, self-reported assessment of their obstacles is practical and inexpensive. Second, although the study is a single center and the sample size was low, it is not a representative of whole Ethiopian diabetic patients. Therefore, caution should be exercised in generalizing our findings. Third, the study was cross-sectional and the selection method might have created a bias toward of obtained responses from patients who attend to the ambulatory clinic are those who usually care about their health. Finally, it could be broadly argued that a focus on patient obstacles is insufficient.

\section{CONCLUSION}

Diabetes mellitus patients in UOGH have several obstacles in everyday life. Obstacles related to patients' relationship with health professionals, lack of support from their friends, lack of knowledge about DM, and lack of motivation to exercise were frequently reported. Effective efforts should be initiated to improve healthier environment to educate, care, and preventive services for people with DM.

\section{ETHICS STATEMENT}

This study was carried out in accordance with the recommendations of ethical clearance committee of the school of pharmacy with written informed consent from all subjects. All subjects gave written informed consent in accordance with the Declaration of Helsinki. The protocol was approved by the institutional ethical committee of University of Gondar-School of Pharmacy.

\section{AUTHOR CONTRIBUTIONS}

All authors listed have made a substantial, direct and intellectual contribution to the work, and approved it for publication.

\section{ACKNOWLEDGMENTS}

We would like to thank Prof. Liina Pilv for providing her support to reuse validated DOQ-30 questionnaire.

(DOQ-30) in six European countries. Eur J General Pract (2016) 22(1):16-22. doi:10.3109/13814788.2015.1093619

7. Assah F, Mbanya JC. Diabetes in Sub-Saharan Africa. Diabetes Mellitus in Developing Countries and Underserved Communities. Springer International Publishing (2017). p. 33-48.

8. Tang TS, Yusuf FL, Polonsky WH, Fisher L. Assessing quality of life in diabetes: II-Deconstructing measures into a simple framework. Diabetes Res Clin Pract (2017) 126:286-302. doi:10.1016/j.diabres.2016.10.007

9. Cummings DM, Lutes L, Littlewood K, DiNatale E, Hambidge B, Schulman K, et al. Regimen-related distress, medication adherence, and glycemic control in rural African American women with type 2 diabetes mellitus. Ann Pharmacother (2014) 48:970-7. doi:10.1177/1060028014536532

10. Spencer MS, Hawkins J, Espitia NR, Sinco B, Jennings T, Lewis C, et al. Influence of a community health worker intervention on mental health outcomes among low-income Latino and African American adults with type 2 diabetes. Race Soc Probl (2013) 5:137-46. doi:10.1007/s12552-0139098-6 
11. Heisler M, Choi H, Palmisano G, Mase R, Richardson C, Fagerlin A, et al. Comparison of community health worker-led diabetes medication decisionmaking support for low-income Latino and African American adults with diabetes using e-health tools versus print materials: a randomized, controlled trial. Ann Intern Med (2014) 18(161):13-22. doi:10.7326/M13-3012

12. Tang TS, Funnell MM, Sinco B, Spencer MS, Heisler M. Peer-led, empowerment-based approach to self-management efforts in diabetes (PLEASED): a randomized controlled trial in an African American Community. Ann Fam Med (2015) 13:27-35. doi:10.1370/afm.1819

13. American Diabetes Association. Standards of medical care in diabetes 2015. Diabetes Care (2015) 38(Suppl 1):S1-93. doi:10.2337/dc15-S001

14. Creative Research System. Available from: http://www.surveysystem.com/ sscalc.html. (Accessed January 4, 2017).

15. Abebe SM, Berhane Y, Worku A, Alemu S. Increasing trends of diabetes mellitus and body weight: a ten year observation at Gondar University Teaching Referral Hospital, Northwest Ethiopia. PLoS One (2013) 8(3):e60081. doi:10.1371/journal.pone.0060081

16. Polonsky WH, Fisher L, Hessler D, Edelman SV. A survey of blood glucose monitoring in patients with type 2 diabetes: are recommendations from healthcare professionals being followed? Curr Med Res Opin (2011) 27:S31-7. doi:10.1185/03007995.2011.599838

17. Houle J, Beaulieu MD, Chiasson JL, Lespérance F, Côté J, Strychar I, et al. Glycaemic control and self-management behaviours in Type 2 diabetes: results from a 1-year longitudinal cohort study. Diabetic Med (2015) 32(9): 1247-54. doi:10.1111/dme.12686

18. Kirk JK, Graves DE, Bell RA, Hildebrandt CA, Narayan KMV. Racial and ethnic disparities in self-monitoring of blood glucose among US adults: a qualitative review. Ethn Dis (2007) 17(1):135-42.

19. Chan JC, Sui Y, Oldenburg B, Zhang Y, Chung HH, Goggins W, et al. Effects of telephone-based peer support in patients with type 2 diabetes mellitus receiving integrated care: a randomized clinical trial. JAMA Intern Med (2014) 174:972-81. doi:10.1001/jamainternmed.2014.655

20. Goff SL, Mazor KM, Meterko V, Dodd K, Sabin J. Patients' beliefs and preferences regarding doctors' medication recommendations. J General Intern Med (2008) 23(3):236-41. doi:10.1007/s11606-007-0470-3

21. Keirns CC, Goold SD. Patient-centered care and preference-sensitive decision making. JAMA (2009) 302(16):1805-6. doi:10.1001/jama.2009.1550

22. SN MY, Nedjat S, Arbabi M, Majdzadeh R. Who is a good doctor? Patients \& physicians' perspectives. Iran J Public Health (2015) 44(1):150-2.

23. Chesla CA, Fisher L, Skaff MM, Mullan JT, Gilliss CL, Kanter R. Family predictors of disease management over one year in Latino and European American patients with type 2 diabetes. Fam Process (2003) 42(3):375-90. doi:10.1111/j.1545-5300.2003.00375.x

24. Kovacs Burns K, Nicolucci A, Holt RI, Willaing I, Hermanns N, Kalra S, et al. Diabetes Attitudes, Wishes and Needs second study (DAWN2 ${ }^{\mathrm{TM}}$ ): crossnational benchmarking indicators for family members living with people with diabetes. Diabetic Med (2013) 30(7):778-88. doi:10.1111/dme.12239

25. Powers MA, Bardsley J, Cypress M, Duker P, Funnell MM, Fischl AH, et al. Diabetes self-management education and support in type 2 diabetes: a joint position statement of the American Diabetes Association, the American Association of Diabetes Educators, and the Academy of Nutrition and Dietetics. J Academy Nutr Dietetics (2015) 115(8):1323-34. doi:10.1016/j. jand.2015.05.012

26. Tarkun I, Özgöksu SD. Attitudes, wishes, and needs of diabetes patients and their relatives: Turkish data from the DAWN2 study. Turkish J Med Sci (2017) 47(2):447-54. doi:10.3906/sag-1509-67

27. Mayberry LS, Osborn CY. Family involvement is helpful and harmful to patients' self-care and glycemic control. Patient Educ counsel (2014) 97(3): 418-25. doi:10.1016/j.pec.2014.09.011

28. McElfish PA, Bridges MD, Hudson JS, Purvis RS, Bursac Z, Kohler PO, et al. Family model of diabetes education with a Pacific Islander community. Diabetes Educ (2015) 41(6):706-15. doi:10.1177/0145721715606806

29. Samuel-Hodge CD, Holder-Cooper JC, Gizlice Z, Davis G, Steele SP, Keyserling TC, et al. Family PArtners in Lifestyle Support (PALS): familybased weight loss for African American adults with type 2 diabetes. Obesity (2017) 25(1):45-55. doi:10.1002/oby.21700

30. Hu J, Wallace DC, McCoy TP, Amirehsani KA. A family-based diabetes intervention for Hispanic adults and their family members. Diabetes Educ (2014) 40:48-59. doi:10.1177/0145721713512682

31. El-Rufaie OE, Bener A, Ali TA, Abuzeid M. Psychiatric morbidity among type II diabetic patients: a controlled primary care survey. Prim Care Psyc (1997) 3:189-94.

32. Aikens JE, Rosland AM, Piette JD. Improvements in illness self-management and psychological distress associated with telemonitoring support for adults with diabetes. Prim Care Diabetes (2014) 9:127-34. doi:10.1016/j. pcd.2014.06.003

33. Kalda R, Ratsep A, Lember M. Predictors of quality of life of patients with type 2 diabetes. J Patient Prefer Adher (2008) 2:21-6.

34. Al-Maskari F, El-Sadig M, Al-Kaabi JM, Afandi B, Nagelkerke N, Yeatts KB. Knowledge, attitude and practices of diabetic patients in the United Arab Emirates. PLoS One (2013) 8(1):e52857. doi:10.1371/journal.pone.0052857

35. Koura MR, Khairy AE, Abdel-Aal NM, Mohamed HF, Amin GA, Sabra AY. The role of primary health care in patient education for diabetes control. J Egypt Public Health Assoc (2001) 76:241-64.

36. Horne R, Weinman J. Patients' beliefs about prescribed medicines and their role in adherence to treatment in chronic physical illness. J Psychosom Res (1999) 47(6):555-67. doi:10.1016/S0022-3999(99)00057-4

Conflict of Interest Statement: The authors report no relationships that could be construed as a conflict of interest.

Copyright (c) 2018 Bhagavathula, Gebreyohannes, Abegaz and Abebe. This is an open-access article distributed under the terms of the Creative Commons Attribution License (CC BY). The use, distribution or reproduction in other forums is permitted, provided the original author(s) and the copyright owner are credited and that the original publication in this journal is cited, in accordance with accepted academic practice. No use, distribution or reproduction is permitted which does not comply with these terms. 